Journal of Cellular Biochemistry 22:87-97 (1983)

Protein Transport and Secretion 33-43

\title{
Transport of Hemolysin by Escherichia coli
}

\author{
Michael Härtlein, Sigrid SchießI, Wilma Wagner, Ursula Rdest, Jürgen Kreft, \\ and Werner Goebel
}

Institut für Genetik und Mikrobiologie, Universität Würzburg, D-8700 Würzburg, West
Germany

The hemolytic phenotype in Escherichia coli is determined by four genes. Two (hlyC and hlyA) determine the synthesis of a hemolytically active protein which is transported across the cytoplasmic membrane. The other two genes (hly $\mathrm{B}_{\mathrm{a}}$ and hly $B_{b}$ ) encode two proteins which are located in the outer membrane and seem to form a specific transport system for hemolysin across the outer membrane. The primary product of gene hlyA is a protein (protein A) of 106,000 daltons which is nonhemolytic and which is not transported. No signal peptide can be recognized at its $\mathrm{N}$-terminus. In the presence of the hlyC gene product (protein $\mathrm{C}$ ), the 106,000 -dalton protein is processed to the major proteolytic product of 58,000 daltons, which is hemolytically active and is transported across the cytoplasmic membrane. Several other proteolytic fragments of the 106,000-dalton protein are also generated. During the transport of the 58,000-dalton fragment (and possible other proteolytic fragments of hlyA gene product), the $\mathrm{C}$ protein remains in the cytoplasm. In the absence of hly $B_{a}$ and hly $B_{b}$ the entire hemolytic activity (mainly associated with the 58,000-dalton protein) is located in the periplasm: Studies on the location of hemolysin in hly $\mathrm{B}_{\mathrm{a}}$ and hly $\mathrm{B}_{\mathrm{b}}$ mutants suggest that the gene product of hly $\mathrm{B}_{\mathrm{a}}$ (protein $\mathrm{B}_{\mathrm{a}}$ ) binds hemolysin and leads it through the outer membrane whereas the gene product of hly $B_{b}$ (protein $B_{b}$ ) releases hemolysin from the outer membrane. This transport system is specific for $\mathrm{E}$ coli hemolysin. Other periplasmic enzymes of $\mathrm{E}$ coli and heterologous hemolysin (cereolysin) are not transported.

Key words: hemolysin, Escherichia coli, gene cloning, expression, transport

Hemolysin is an extracellular protein toxin which is produced by some strains of Escherichia coli, particularly those which cause extraintestinal infections in man $[1,2]$. Its direct involvement in the pathogenesis of such infections appears very likely $[3,4]$. The hemolytic phenotype, ie, the synthesis of active hemolysin and its secretion into the surrounding medium is controlled by extrachromosomal or chromosomal genes $[1,5,6]$, which have been shown to be structurally and functionally closely related [6,7]. The transport of hemolysin is of particular interest since hemolysin belongs to the few proteins produced by gram-negative bacteria which are transported across both the cytoplasmic and outer membranes. Previous genetic data have indi-

Received May 8, 1983; revised and accepted June 20, 1983.

(C) 1983 Alan R. Liss, Inc. 


\section{8:JCB Härtlein et al}

cated that a specific transport system determined by two of the hly genes is responsible for the transport of hemolysin across the outer membrane $[6-8,11]$.

We present here data on the identification of the two proteins which make up this hemolysin-specific transport system. We also report studies which indicate that the transport of hemolysin across the cytoplasmic membrane proceeds in a rather unconventional way involving the proteolytic processing of a precursor protein of 106,000 daltons to a cleavage product of 58,000 daltons which, under the influence of another gene (hlyC), becomes hemolytically active.

Bacterial strains and plasmids have been described previously.

Transposon mutagenesis, complementation analysis, construction of recombinant DNAs and deletion mutants, cleavage of DNA with restriction enzymes, and hemolysinassay were performed as described $[10,11]$.

Cell-fractionation was achieved by a modified method of Koshland and Botstein [21] or by the procedure of Osborn et al [14]. Separation of proteins of the outer and inner membrane was carried out as described by Schnaitman [25].

Plasmid-specified proteins were determined in mini cells [12] or in the maxi cell system described recently by Sancar et al [13]. Labeling of proteins was performed with ${ }^{35} \mathrm{~S}$-methionine, and proteins were separated on polyacrylamide gels containing sodium dodecyl sulfate (SDS.)

\section{RESULTS}

Secretion of hemolysin by $\mathrm{E}$ coli into the surrounding media is highest during the active growth phase [10]. More than $50 \%$ of total hemolysin produced by the hemolytic E coli strain $\mathrm{K}-12$ (pHly 152) is detected in a cell-free form as a protein with a molecular weight of about 60,000 daltons. The residual part of active hemolysin remains preferentially in the outer membrane and the periplasmic space $[10$, and unpublished results]. Transport of hemolysin across the outer membrane does not seem to be accompanied by partial lysis of the cells since neither cytoplasmic $(\beta$ galactosidase) nor periplasmic ( $\beta$-lactamase) proteins are found in the supernatant during the period of maximal hemolysin release.

As described previously $[8,11,15]$, four genes located in the order hlyC, hlyA, hly $\mathrm{B}_{\mathrm{a}}$, and hlyB $\mathrm{B}_{\mathrm{b}}$ on transmissible plasmids [8] or the chromosome [15] of $\mathrm{E}$ coli determine the hemolytic phenotype, ie, synthesis and secretion of active hemolysin. All mutations in hlyC and most in hlyA destroy hemolytic activity completely. But nonhemolytic mutants were isolated which are still able to produce active hemolysin but do not secrete it. As shown in Table I, mutations leading to this phenotype can affect three of the four hly genes, ie, hlyA, hlyB $\mathrm{B}_{\mathrm{a}}$, and hlyB $\mathrm{B}_{\mathrm{b}}$. Mutations in hlyA leading to the production of internal hemolysin which is not secreted are always located at the $3^{\prime}$ end of hlyA, ie, it affects the C-terminus of the hlyA gene product.

The hemolytic activity of these mutants is mainly detected in the cytoplasm or the cytoplasmic membrane and little is found in the periplasmic space. It thus appears that these mutants synthesize a still active hemolysin that is impaired in the transport across the cytoplasmic membrane (and possibly also across the outer membrane).

In $\mathrm{hlyB}_{\mathrm{a}}$ mutants hemolysin is found preferentially in the periplasmic space and the cytoplasmic membrane. Little is associated with the outer membrane, thus indicating that transport across the outer membrane is impaired. 
TABLE 1. Hemolysin Activity of Hly Plasmid Mutants Deficient in Transport of Hemolysin*

\begin{tabular}{|c|c|c|c|c|c|}
\hline Mutant plasmid & $\begin{array}{c}\text { Cell-free } \\
\text { hemolysin } \\
\text { activity }^{\mathbf{a}}\end{array}$ & $\begin{array}{c}\text { Cytoplasmic } \\
\text { hemolysin } \\
\text { activity }\end{array}$ & $\begin{array}{c}\text { Periplasmic } \\
\text { hemolysin } \\
\text { activity }^{\mathrm{a}}\end{array}$ & $\begin{array}{c}\text { Membrane- } \\
\text { associated } \\
\text { hemolysin } \\
\text { activity }^{\mathbf{a}}\end{array}$ & $\begin{array}{l}\text { Mutated } \\
\text { gene }^{\text {d }}\end{array}$ \\
\hline \multicolumn{6}{|l|}{ Control } \\
\hline pHly 152 & 75 & 20 & 25 & 15 & \\
\hline \multicolumn{6}{|l|}{ I } \\
\hline pHly 152::Tn5-1 & - & 26 & 62 & $12^{\mathrm{b}}$ & hlyB $\mathrm{a}_{\mathbf{a}}$ \\
\hline pHly $152:: \operatorname{Tn} 5-23$ & - & 18 & 71 & 17 & hlyB $\mathrm{B}_{\mathrm{a}}$ \\
\hline pANN202-312::Tn5-2 & - & 20 & 65 & 9 & hlyBa \\
\hline \multicolumn{6}{|l|}{ II } \\
\hline pHly 152::Tn5-5 & - & 16 & 48 & $36^{c}$ & hlyB $B_{b}$ \\
\hline pHly I52::Tn5-19 & - & 32 & 42 & 38 & hlyB $B_{b}$ \\
\hline pANN202-312::Tn5-10 & - & 24 & 28 & 43 & hlyB $B_{b}$ \\
\hline \multicolumn{6}{|l|}{ III } \\
\hline pHly 152::Tn5-4 & - & 60 & 5 & $40^{b}$ & hlyA \\
\hline pHly 152::Tn5-11 & - & 55 & 6 & 50 & hlyA \\
\hline pANN202-3124 & 一 & 72 & 8 & 47 & hlyA \\
\hline
\end{tabular}

*Mutants were obtained by transposon mutagenesis of plasmids pHly 152 [5] or pANN202-312 [8].

${ }^{a} \mathrm{Hemolysin}$ activity is given in arbitrary units as previously described [11].

bemolysin activity is mainly in the inner membrane.

${ }^{c}$ Hemolysin activity is mainly in the outer membrane.

${ }^{d}$ For the definition and location of the genes, hlyA, hlyB $\mathrm{a}_{\mathrm{a}}$, and hly $\mathrm{B}_{\mathrm{b}}$, see [11].

Mutants blocked in gene hly $\mathrm{B}_{\mathrm{b}}$ form small hemolysis zones on erythrocyte-agar plates around the growing colonies, suggesting that some hemolysin is already exposed on the cellular surface. This observation agrees with the finding that most of the active hemolysin produced by these mutants is detected in the outer membrane and the periplasm. The analysis of the mutants impaired in the transport of hemolysin thus indicates that secretion of hemolysin by the $\mathrm{E}$ coli cells is accomplished by two separate transport systems, one for the cytoplasmic membrane, which involves at least in part gene hlyA, and one for the outer membrane, which involves the functions of both genes, hly $\mathrm{B}_{\mathrm{a}}$ and hlyB $\mathrm{B}_{\mathrm{b}}$.

In order to study the gene products of the hly genes and their interactions in the synthesis and transport of hemolysin we constructed a set of recombinant DNAs carrying the individual genes and all possible combinations $[8,11]$. HlyC, hly $\mathrm{B}_{\mathrm{a}}$, and hly $_{b}$ could be cloned on multicopy plasmid vectors and the expression of these genes was partially increased by the linkage of the lac promoter in front of the genes. HlyA, in contrast, could not be cloned on the same vectors and when cloning was achieved in pHSF1 and brought under the control of the right $\lambda$ promoter $\left(P_{R}\right)$ together with the temperature inducible $\lambda$ repressor $\left(\mathrm{CI}_{857}\right)$, it was found that induction of hlyA gene expression at $42^{\circ} \mathrm{C}$ is a lethal event to the cell [8]. The products of the hly genes were determined in mini cells and maxi cells $[12,13]$, into which these recombinant plasmids were transformed. As previously shown [8], induction of the hlyA gene leads in mini cells to the expression of a 106,000-dalton protein, which is apparently the primary gene product of hlyA. This protein $\mathrm{A}$ is nonhemolytic and, as shown by cell fractionation, remains exclusively in the cytoplasm. 


\section{0:JCB Härtlein et al}

Complementation of these cells with a recombinant plasmid carrying hlyC leads to cells viable at $42^{\circ} \mathrm{C}$ which form active hemolysin that is effectively transported across the cytoplasmic membrane (Table II). The same results are obtained with cells carrying one recombinant plasmid with hlyC and hlyA linked together. A plasmid with a temperature-sensitive mutation in hlyC synthesizes and transports hemolysin normally at $30^{\circ} \mathrm{C}$ but at $42^{\circ} \mathrm{C}$ both events are blocked (Table II). These results indicated that both hly $\mathrm{A}$ and hlyC are required for producing active hemolysin and for its concomitant transport across the inner membrane. How is this accomplished? Analysis of hlyC in maxi cells shows the expression of a protein of 18,000 daltons (Fig. 1a) that is cytoplasmic and nonhemolytic. This protein disappears after $\operatorname{Tn} 5$ insertion into hlyC (Fig. 1b). Maxi cells containing hlyC and hlyA yield a complex pattern (Fig. 2). Small amounts of the 106,000-dalton protein (the primary product of hlyA) can still be detected in addition to large amounts of protein C. Several new protein bands also appear, ranging in size from 30,000 to 90,000 daltons, depending on the labeling time. Pulse/chase experiments indicate that the 106,000-dalton protein is converted to these smaller proteins, a protein of 58,000 daltons being the major species among these proteolytic products (Fig. 3). This protein is predominantly

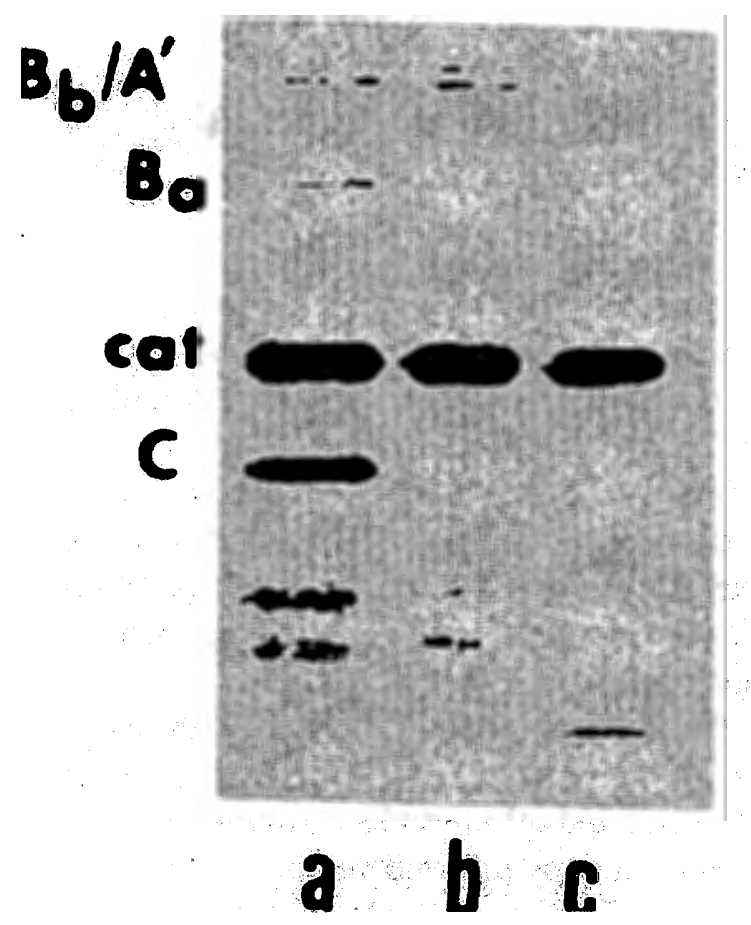

Fig. 1. Analysis on SDS-polyacrylamide gels of proteins synthesized in maxi cells carrying pANN202312 (a) and a mutant of it with a Tn5 insertion in hlyC, pANN202-312 Tn5-4 (b). Lane c shows the vector proteins of pACYC184 (cat with a molecular weight of 22,000 daltons and the major $\mathrm{Tc}^{\mathrm{R}}$ gene product, which has a molecular weight of 40,000 daltons. This protein is lost in the recombinant plasmids.) The used vector plasmid pACYC184 is described in [31]. Maxi cells were labeled for $20 \mathrm{~min}$ with ${ }^{35} \mathrm{~S}$-methionine as described [13]. Plasmid pANN202-312 is a recombinant DNA into which the entire hly determinant, eg, hlyA, hlyC hlyB $B_{a}$, and hlyB $B_{b}$, has been inserted [8]. Protein $C$ is the gene product of hlyC (18,000 daltons); cat is chloramphenicol acetyltransferase determined by the vector and $A^{\prime} ; B_{b}$ and $B_{a}$ are gene products of the other hly genes (see text). The protein band above the position of $B_{b}$ in lane $b$ represents protein determined by Tn5. The disappearance of $A$ and $B_{a}$ in lane $b$ is due to the polar effect of $\mathrm{Tn} 5$ [11]. Electrophoresis was carried out on $17.5 \%$ polyacrylamide according to Laemmli [30]. 
TABLE II. Combination of hlyA and hlyC Leads to the Synthesis of Active Hemolysin and Its Transport Across the Inner Membrane

\begin{tabular}{|c|c|c|c|c|}
\hline $\begin{array}{l}\text { Combination of } \\
\text { hly genes }\end{array}$ & $\begin{array}{c}\text { Cytoplasmic } \\
\text { hemolysin } \\
\text { activity }\end{array}$ & $\begin{array}{c}\text { Periplasmic } \\
\text { hemolysin } \\
\text { activity }\end{array}$ & $\begin{array}{c}\text { Membrane-associated } \\
\text { hemolysin activity }\end{array}$ & $\begin{array}{c}\text { Cell-free } \\
\text { hemolysin activity }\end{array}$ \\
\hline hlyA $^{a}$ & - & - & - & - \\
\hline hly $A+$ hlyC $C^{a}$ & 22 & 70 & 15 & - \\
\hline hlyCts + hlyA $\left(30^{\circ} \mathrm{C}\right)$ & 25 & 55 & 12 & - \\
\hline hlyCts + hlyA $\left(42^{\circ} \mathrm{C}\right)$ & - & - & 一 & - \\
\hline
\end{tabular}

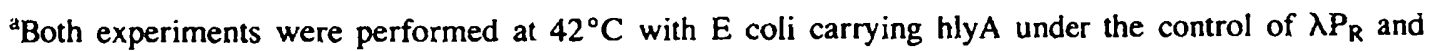
$\mathrm{CI}_{\mathrm{ts857}}[8]$.

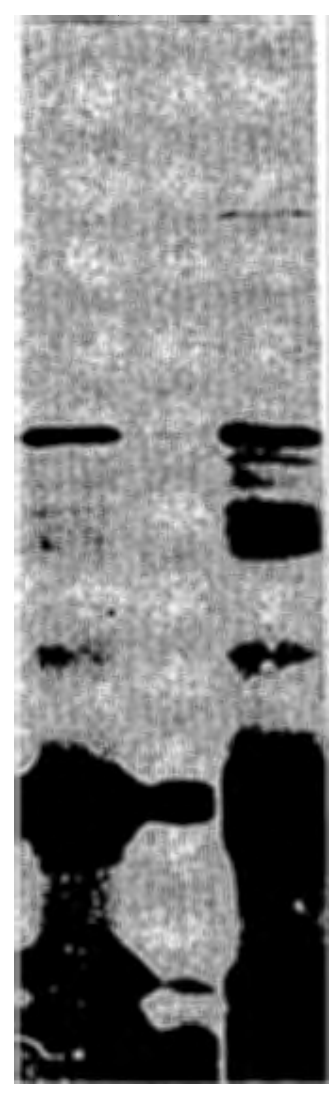

2

b

\section{$106 \mathrm{k}$ (A) \\ $90 \mathrm{k}$ \\ $75 \mathrm{k}$ \\ $58 \mathrm{~K}\left(\mathrm{~A}^{\prime}\right)$}

$30 \mathrm{k}$

cat

$18 k(C)$

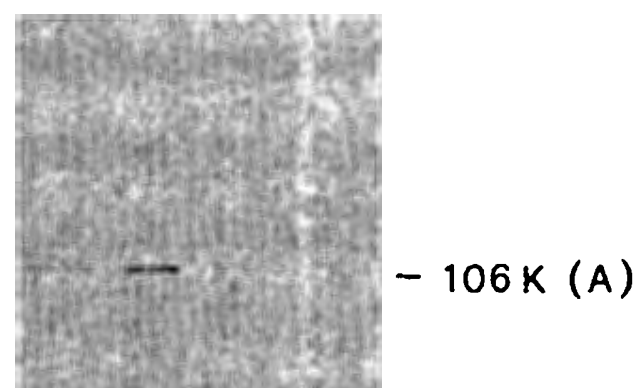

$-58 K\left(A^{\prime}\right)$

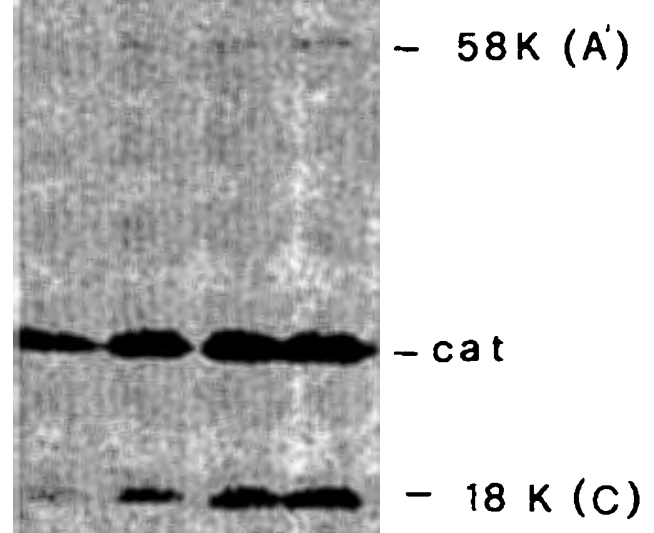

Fig. 2. SDS-polyacrylamide gel electrophoresis of proteins synthesized in maxi cells carrying the recombinant plasmid pANN202-3128 which contains hlyA and hlyC [11]. Labeling of the proteins with ${ }^{35} \mathrm{~S}$-methionine was performed for $10 \mathrm{~min}$ (a) and for $2 \mathrm{~min}(\mathrm{~b})$. The proteins of the vector plasmid pACYC184 are as indicated in Figure 1 , lane c.

Fig. 3. Analysis of proteins labeled with ${ }^{35} \mathrm{~S}$-methionine in maxi cells [13] carrying pANN202-3128 for various times. (a) label for $3 \mathrm{~min}$, (b) label for $5 \mathrm{~min}$, (c) label for $8 \mathrm{~min}$, (d) label for $3 \mathrm{~min}$, and chase for $30 \mathrm{~min}$ with a 50 -fold excess of cold methionine. Vector pACYC184 encoded proteins are shown in Figure 1, lane $c$. 


\section{2:JCB Härtlein et al}

found in the periplasmic space together with some other proteolytic fragments of hlyA gene product, indicating that these fragments, in contrast to the 106,000 dalton primary gene product of hlyA, are capable of being transported across the cytoplasmic membrane. To test whether the proteolytic processing of protein A (106,000 daltons) is catalyzed by hlyC gene product, a recombinant DNA was constructed carrying an intact hly $\mathrm{A}$ gene but a mutated hlyC gene, which determines a temperature-sensitive protein $\mathrm{C}$ which does not function at $42^{\circ} \mathrm{C}$.

As shown in Figure 4, processing of $\mathrm{A}$ protein is reduced at $42^{\circ} \mathrm{C}$ compared to $30^{\circ} \mathrm{C}$, but as judged from the intensities of the protein bands of the PA gels (Fig. 4b, $\mathrm{d})$, it is reduced to the same extent in strains carrying normal hlyC and hlyA or $\mathrm{hlyC}_{\mathrm{ts}}$, and hlyA. This seems to indicate that protein $\mathrm{C}$ is not required for the proteolysis of protein $\mathrm{A}$ and hence the transport of the 58,000-dalton protein. Under the restrictive conditions no hemolytic activity is detected in the hly $\mathrm{C}_{\mathrm{ts}}$, hlyA strain but is in the hlyC, hlyA strain, indicating that the proteolytic processing of protein $\mathrm{A}$ is not sufficient for generating hemolytic activity of the protein A fragments. Since protein $\mathrm{C}$ remains always in the cytoplasm, we assume that the hemolytic activity of the transported protein $\mathrm{A}$ fragments is brought about by an as-yet-unknown enzymatic reaction catalyzed by protein $\mathrm{C}$.

Similar conclusions are indicated by another set of data. As indicated before, hlyA mutants obtained by Tn5 insertion at the C-terminal end of hlyA synthesize active hemolysin which is poorly transported across the cytoplasmic membrane. A similar hlyA mutant was generated by deleting about 60 base pairs (bp) from the 3' end of hlyA by a partial Psti cleavage of a suitable recombinant DNA [8]. This mutant (pANN202-3124) synthesizes active internal hemolysin, provided functioning protein $\mathrm{C}$ is present, but this hemolysin remains predominantly in the cytoplasm or is found associated with the cytoplasmic membrane (Table I).

Analysis of the proteins synthesized in maxi cells containing this recombinant plasmid is shown in Figure 5. The major protein (besides protein $\mathrm{C}$ and cat protein deriving from the vector cat gene) is now a 104,000-dalton polypeptide which is obviously the product of the truncated hlyA gene and this product is found mainly in the cytoplasm. Little proteolytic processing of this product to smaller fragments is seen even after an extended chase period. This further suggests that proper transport across the cytoplasmic membrane requires the proteolytic processing of the protein $A$ and that this processing may be caused by an autoproteolytic activity of protein $\mathrm{A}$ which is located near the $\mathrm{C}$-terminal end of this protein. Protein $\mathrm{C}$ can apparently activate not only the transportable proteolytic fragments of protein $\mathrm{A}$ but also non- or poorly processed protein A to hemolytic activity. It thus appears that transport and activation of the fragments of protein A (mainly the 58,000-dalton fragment) are not necessarily linked processes.

The hemolytic activity (mainly determined by the 58,000-dalton fragment of protein A) remains predominantly in the periplasm and little is found associated with the outer membrane when $\mathrm{E}$ coli cells contain only hlyC and hlyA. The addition of a recombinant $\mathrm{DNA}$ carrying hlyB $_{\mathrm{a}}$ leads to the accumulation of hemolysin in the outer membrane, but no hemolysin is detected in a cell-free form during the logarithmic growth phase (Table III). Complementation of hlyC- and hlyA-containing cells with hly $B_{b}$ does not influence the periplasmic pool of the hemolysin (Table III), whereas complementation with a recombinant DNA carrying both hlyB $\mathrm{B}_{\mathrm{a}}$ and hly $\mathrm{B}_{\mathrm{b}}$ [11] leads to transport of hemolysin across the outer membrane and more than $50 \%$ of total 


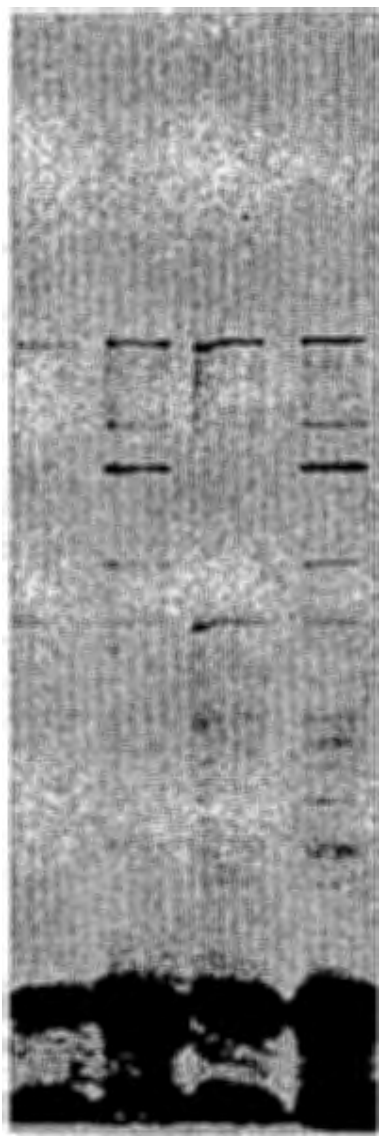

4
$106 k$

$75 k$

$68 k$ $58 K$
$106 \mathrm{~K}$

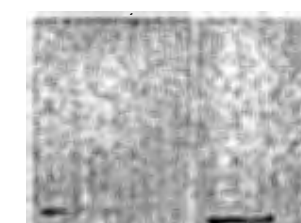

$58 \mathrm{~K}$

Fig. 4. Analysis of proteins labeled with ${ }^{35} \mathrm{~S}$-methionine in maxi cells carrying pANN202-3128 with wild-type hlyC gene $(\mathrm{a}, \mathrm{b})$ and with a temperature-sensitive hlyC $(\mathrm{c}, \mathrm{d})$. In a and $\mathrm{c}$ labeling of proteins was carried out for $10 \mathrm{~min}$ at $30^{\circ} \mathrm{C}$ and in $\mathrm{b}$ and $\mathrm{d}$ for $3 \mathrm{~min}$ at $42^{\circ} \mathrm{C}$. The most prominent protein band (at the bottom of the gel) represents the vector pACYC184-encoded cat.

Fig. 5. Analysis of proteins synthesized in maxi cells carrying pANN202-3128 (a) and pANN202-3124 (b). In a and b labeling of maxi cells was performed for 10 min at $37^{\circ} \mathrm{C}$. The protein extracts of a and $\mathrm{b}$ were run in two different gels. The vector pACYC184-encoded proteins are as indicated in Figure $1 \mathrm{c}$.

hemolytic activity is found in the supernatant, ie, in a cell-free state. These data agree with previous data (Table I) which had shown that hlyB $\mathrm{B}_{\mathrm{a}}$ mutants contain most of their hemolysin in the periplasm, whereas hly $_{\mathrm{b}}$ mutants show a substantial amount of the hemolysin associated to the outer membrane but not yet released. Both lines of data suggest that the two genes, hly $B_{a}$ and $h l y B_{b}$, form a transport system for hemolysin across the outer membrane. The gene product of hlyB $\mathrm{B}_{\mathrm{a}}$ seems to bind hemolysin to the outer membrane and leads it across, whereas the gene product of hly $B_{b}$ releases hemolysin from the outer membrane. The two proteins determined by hly $\mathrm{B}_{\mathrm{a}}$ and hly $\mathrm{B}_{\mathrm{b}}$ have been recognized in mini cells carrying a recombinant plasmid, pANN205-222, which carries hlyB $B_{a}$ and hly $B_{b}$ under the control of the lac promoter [11] (Fig. 6). The amount synthesized under the control of this relatively strong promoter is rather low. Protein $B_{a}$, as determined by a separate plasmid (pANN250- 
94:JCB Härtlein et al

TABLE III. Effect of hlyB $\mathrm{a}_{\mathrm{a}}$ and $\mathrm{hlyB}_{\mathrm{b}}$ Functions on the Transport of Hemolysin Across the Outer Membrane

\begin{tabular}{|c|c|c|c|c|c|}
\hline \multirow{2}{*}{$\begin{array}{l}\text { Combination of } \\
\text { hly genes }^{\mathrm{a}}\end{array}$} & \multirow{2}{*}{$\begin{array}{l}\text { Hemolytic } \\
\text { activity in the } \\
\text { periplasm }\end{array}$} & \multirow{2}{*}{$\begin{array}{c}\text { Total activity } \\
\text { in the membrane } \\
\text { fraction }\end{array}$} & \multicolumn{2}{|c|}{$\begin{array}{l}\text { Percent of total hemolytic activity } \\
\text { of the membrane fraction }\end{array}$} & \multirow{2}{*}{$\begin{array}{l}\text { Cell-free } \\
\text { hemolysin }\end{array}$} \\
\hline & & & Inner membrane & Outer membrane & \\
\hline hlyA & - & & - & - & - \\
\hline hlyA + hlyC & 75 & 25 & 70 & $<30$ & - \\
\hline hlyA + hlyC + hlyB & 45 & 40 & $<20$ & 80 & $-^{b}$ \\
\hline $\begin{array}{l}\text { hly } A+\text { hlyC }+ \text { hlyB } B_{b} \\
\text { hly } A+\text { hlyC }+ \text { hlyB }\end{array}$ & 72 & 26 & 75 & $<30$ & - \\
\hline+ hlyB $_{\mathrm{b}}$ & 25 & 25 & $<10$ & 90 & 75 \\
\hline
\end{tabular}

${ }^{a}$ Combination was done by transformation of recombinant plasmids carrying the hly genes separately or in combinations (hlyA + hlyC or $h_{l y B}+h l y B_{b}$ ). These recombinant DNAs have been recently described $[8,11]$.

${ }^{b}$ Cell-free hemolysin is not detected in the supernatant of the cell culture, but colonies show already a small hemolytic zone on erythrocyte-agar plates.

222, [11]), has a molecular weight of 46,000 daltons and is found in the outer membrane (Fig. 7). Protein $B_{b}$ has a molecular weight of 62,000 daltons and is also found predominantly in the outer membrane (Fig. 7) but some protein $B_{b}$ always remains in the cytoplasmic membrane fraction, when cell fractionation is performed by the procedure of Osborn et al.

This transport system seems to be highly specific for E coli hemolysin. Two other periplasmic enzymes tested, alkaline phosphatase and $\beta$-lactamase, were not released into the medium by $\mathrm{E}$ coli cells carrying $\mathrm{hlyB}_{\mathrm{a}}$ and $\mathrm{hlyB}_{\mathrm{b}}$, nor was a hemolysin (cereolysin) from Bacillus cereus transported across the outer membrane by this system. The gene for cereolysin was cloned in a shuttle vector, which was transformed into two heterologous bacterial hosts [16]. In $E$ coli expression of the hemolysin gene was achieved but only a poor transport across the inner membrane and no transport across the outer membrane were observed [16].

Release of hemolysin from E coli cells was only obtained after long incubation, probably due to partial lysis of the cells. In contrast, hemolysin was efficiently transported across the membrane of the gram-positive Bacillus subtilis cells and released into the medium. There is preliminary evidence that this hemolysin is determined by a single gene and that its primary gene product contains a signal peptide, which is apparently perfectly well recognized by the cytoplasmic membrane of $B$ subtilis, but less efficiently by the cytoplasmic membrane of $E$ coli and not at all by the outer membrane of $\mathrm{E}$ coli $[\mathrm{Kreft} \mathrm{J}$, Gilmore $\mathrm{M}$, Goebel W, unpublished results].

\section{DISCUSSION}

Hemolysin synthesized by some $\mathrm{E}$ coli strains is one of the few proteins of gram-negative bacteria which are transported across both the cytoplasmic and outer membranes. In most cases studied transportable proteins in these bacteria are able to cross the inner membrane with the help of a signal peptide present at the $\mathrm{N}$-terminal end of the protein $[17,18]$ and are subsequently caught in the periplasmic space [19- 


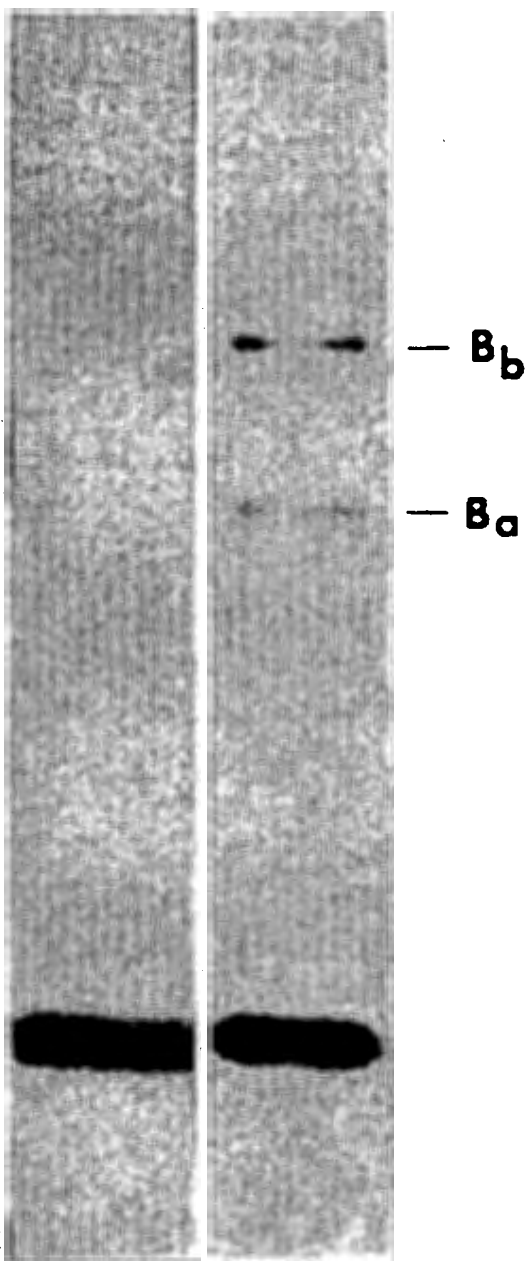

6

b

Fig. 6. Proteins determined by a recombinant plasmid, pANN205-222 $[11]$, which carries hly $B_{a}$ and hlyB $_{b}$, expressed and labeled with ${ }^{35} \mathrm{~S}$-methionine in mini cells for $20 \mathrm{~min}$ at $37^{\circ} \mathrm{C}$. (a) vector pUR222;(b) pA.NN205-222 [32].

Fig. 7. Localization of proteins $B_{a}$ and $B_{h}$ in the outer membrane of $E$ coli. Mini cells carrying pANN205-222 [11] were labeled with ${ }^{35}$ S-methionine. Cells were subsequently fractionated as described by Osborn et al [14] and proteins from the various fractions were analyzed on SDS-polyacrylamide gels. (a) L.1-band, (b) L2-band (L.I and L2 represent cytoplasmic membranc fractions), (c) M-band, and (d) $H$-band (both fractions, $M$ and $H$, contain mainly outer membrane).

$22]$ or integrated into the outer membrane $[23,24]$. The information for this compartmentation scems to be inherent in the structure of the polypeptide. Hemolysin of $\mathrm{E}$ coli is found in the supernatant, ie, in a cell-free state and in an osmotic shock fluid, ie, in the periplasm predominantly as a protein with an average molecular weight of about 60,000 daltons [10] although larger forms are also obtained, especially from the internal hemolysin pool, which have been interpreted as membrane-associated complexes [Springer and Gocbel, unpublished results].

Genetic and biochemical data indicate that the primary gene product from which hemolysin derives is a considerably larger protein with a molecular weight of 106,000 


\title{
met thr thr vol thr thr alo gin leu lys ser thr leu GTIAAGAGgTAATTAAATGACAACAGTAACCACTGCACAAATTAAAAGCACACTG
}

gin phe alo by gin ser val ala ospn lys leu his ser alo gly gin ser thr CAG TCT GCA AAG CAA TCC GCT GCA AAT AAA TTG CAC TCA GCA GGA CAAAGCAC

\author{
lys osp olo leu lys lys olo olo glu gin thr arg ospn \\ G AAA GAT GCA TTA AAA AAA GCA GCA GAG CAA ACC CGA AAT.....
}

Fig. 8. Nucleotide sequence of the $5^{\prime}$-end of hlyA gene and the amino acid sequence of the N-terminal end of protein $A$ derived from it. Underlined sequence represents the presumptive ribosome binding site. Further details of the hlyA sequence will be presented somewhere else.

in daltons (protein A). This protein is unable to cross the cytoplasmic membrane and is per se nonhemolytic. The amino acid sequence at the $\mathrm{N}$-terminal end of protein $\mathrm{A}$ (derived from the nucleotide sequence of the gene hlyA, Fig. 8) does not possess the characteristic properties of a signal peptide [17,18]. Transport is only accomplished upon proteolytic degradation of protein $\mathrm{A}$. One major proteolytic fragment, a protein of 58,000 daltons, appears in the periplasm and pulse/chase experiments show the direct descent of this 58,000-dalton protein from protein A. Additional larger and smaller proteolytic fragments of protein $\mathrm{A}$ are also generated, which may represent intermediates and further degradation products of the 58,000-dalton protein. Some of them seem to be also able to cross the inner membrane. The proteolytic activity may be inherent to protein A since removal of about $60 \mathrm{bp}$ from the $3^{\prime}$ end of hlyA leads to a truncated protein of 104,000 daltons which is only slowly degraded and poorly transported across the inner membrane. The mechanism by which the proteolytic fragment(s) of protein $\mathrm{A}$ is transported is unknown. One possibility is the generation (by a proteolytic cut) of a $\mathrm{N}$-terminal end of the 58,000-dalton fragment (and possibly of other fragments) which can act as a signal peptide, thus allowing the transport of the fragment(s) across the inner membrane in the conventional way [17-23]. The function of protein $C$ is necessary to provide the hemolytic activity to the transportable (and probably also to nontransportable) proteolytic fragment(s) of protein A but it does not seem to be directly or indirectly involved in the transport process. It remains in the cytoplasm and $\mathrm{E}$ coli, carrying a mutated hlyC which determines a temperaturesensitive protein $\mathrm{C}$, still shows normal proteolytic degradation of protein $\mathrm{A}$ and transport of its - due to the lack of a functioning protein $\mathrm{C}-$ nonhemolytic fragment(s).

Hemolysin, defined predominantly as the protein $\mathrm{C}$-activated 58,000-dalton fragment of protein $A$ is further transported across the outer membrane in the logarithmic growth phase, whereas no secretion is observed in the stationary phase [10]. Whereas release of periplasmic or membrane-bound proteins from gram-negative bacteria is often caused by a partial cell lysis [26-28], this is clearly not the mechanism by which hemolysin is secreted into the surrounding media. This transport across the outer membrane appears to be achieved by a specific system, genetically defined by two genes, hly $B_{a}$ and $h_{l y B_{b}}$. These genes encode two proteins, $B_{a}$ and $B_{b}$, which have been identified in the outer membrane. The cellular concentration of these proteins is very low, which suggests that transport of hemolysin through the outer membrane occurs only at rather limited sites in the membrane. Genetic and biochemical data indicate that protein $B_{a}$ binds hemolysin to the outer membrane and leads it 
through whereas protein $B_{b}$ releases hemolysin, already exposed to the outside, from the cell.

There does not seem to be a substantial modification of the hemolysin during this transport process since cell-free and periplasmic hemolysin have similar properties and both possess an average molecular weight to be specific for $\mathrm{E}$ coli hemolysin since other periplasmic proteins of $\mathrm{E}$ coli and even a heterologous hemolysin (cereolysin) which was brought into E coli by gene cloning could not be transported across the outer membrane. There is genetic evidence that pilus proteins of $\mathrm{E}$ coli which have to be also transported across the outer membrane require for their transport similar specific transport proteins located in the outer membrane 129; Normarks, personal communication; Hacker $\mathrm{J}$, unpublished results].

\section{ACKNOWLEDGMENTS}

These studies were supported by a grant from the Deutsche Forschungsgemeinschaft (SFB 105-A 12). The excellent technical assistance of M. Vogel is greatly appreciated. We thank $C$. Hughes for critical reading of the manuscript and E. Appel for her help in its preparation.

\section{REFERENCES}

1. Minshew BH, Jörgensen J, Counts GW, Falkow S: Infect Immunol 20:50, 1980.

2. Hughes C, Phillips R, Roberts AR: Infect Immunol 35:270, 1982.

3. Welch RA, Dellinger EP, Minshew B, Falkow S: Nature 294:665, 1981.

4. Hughes C, Hacker J, Roberts A, Goebel W: Infect Immunol 39:546, 1983.

5. Goebel W, Royer-Pokora B, Lindenmaier W, Bujard H: J Bacteriol 118:964, 1974.

6. Müller D, Hughes C, Goebel W: J Bacteriol 153:846, 1983.

7. De la Cruz F, Müller D, Ortiz JM, Goebel W: J Bacteriol 143:825, 1980.

8. Goebel W, Hedgpeth J: J Bacteriol 151:1290, 1982.

9. Schnaitman C: J Bacteriol 108:545, 1971.

10. Springer W, Goebel W: J Bacteriol 144:53, 1980.

11. Wagner W, Vogel M, Goebel W: J Bacteriol 154:200, 1983.

12. Adler A, Fischer NWD, Cohen A, Hardigre AA: Proc Natl Acad Sci USA 57:312, 1967.

13. Sancar A, Hack AM, Rupp WD: J Bacteriol 137:692, 1979.

14. Osborn MJ, Gander JE, Parisi E, Carson J: I Biol Chem 247:3962, 1972.

15. Berger H, Hacker J, Juarez A, Hughes C, Goebel W: J Bacteriol 152:1241, 1982.

16. Kreft J, Berger H, Härtlein M, Müller B, Weidinger G, Goebel W: J. Bacteriol (in press).

17. Blobel G: In Brinkley BR, Porter KR (ed): “The Signal Hypothesis." New York: Rockefeller, 1977, pp 318-325.

18. Chang CN, Blobel G, Model P: Proc Natl Acad Sci USA 75:361, 1978.

19. Clement JM, Perrin D, Hedgpeth J: Mol Gen Genet 185:302, 1982.

20. Inouye H, Beckwith J: Proc Natl Acad Sci USA 74: 1440, 1977.

21. Koshland D, Botstein D: Cell 20:749, 1980.

22. Randall L, Hardy S, Josefsson LG: Proc Natl Acad Sci USA 75:1209, 1978.

23. Braun-Breton C, Hofnung M: J Bacteriol 148:845, 1981.

24. Hedgpeth J, Clement JM, Marchal C, Perrin W, Hofnung M: Proc Natl Acad Sci USA 77:2621, 1980.

25. Schnaitman CA: J Bacteriol 108:545, 1971.

26. Jakes KS, Model P: J Bacteriol 138:770, 1979.

27. Pugsley AP, Rosenbusch JP: J Bacteriol 147:186, 1981.

28. Varenne S, Cavard D, Lazdunski: Eur J Biochem 116:615, 1981.

29. Kehoe M, Sellwood R, Shipley P, Dougan G: Nature 291:122, 1981.

30. Laemmli UK: Nature 227:680, 1970.

31. Chang ACY, Cohen SN: J Bacteriol 134:1141, 1978.

32. Rüther U, Koenen M, Otto K, Müller-Hill B: Nucleic Acids Res 9:4087, 1981. 